\title{
Assessing and Treating Adolescent Suicidality
}

\section{Kristin L. Wolfe, Katia M. Goga, and Betsy D. Kennard}

\begin{abstract}
Adolescent suicide is a growing national public health challenge. Assessment and treatment of teenagers with suicidality (ideation, plans, intent) is critically needed. Comprehensive assessment of individual, family, and environment factors are key. Chain analysis of sequences of behavior and interaction in stressful interpersonal interactions can provide valuable clinical information for use in a range of psychotherapeutic intervention approaches.
\end{abstract}

You receive a call from the emergency department downstairs. They want you to interview a female teenager for possible admission after an interrupted suicide attempt. Upon returning from school yesterday afternoon, the girl went into her parents' bedroom, grabbed a revolver kept near the bed, and went outside with it. Her father came home from work and found his daughter crying in the backyard, with the revolver in her hands. After he convinced her to hand over the weapon, he took his daughter to the emergency room. When you arrive downstairs, you are met with a frantic mother and a grieving father. They look at you, desperate for some answers. What actually happened, and why? How serious is the suicide risk?

\section{Incidence/Prevalence}

Adolescent suicide has become a national health crisis. The Center for Disease Control and Prevention (CDC) reports it as the second-leading cause of death among youth, ages 15-19 years (CDC, 2015). A recent study found that the number of youth who presented to children's hospitals from 2008 to 2015 has almost doubled (.66\% to $1.82 \%$; Plemmons et al., 2018). In 2015, 2,061 adolescent suicide deaths were reported, accounting for $18 \%$ of all reported deaths in this age group.

The CDC examined these data by gender and found that 5.1 per 100,000 females, compared to 14.3 per 100,000 males, died by suicide (CDC, 2015). Females tend to have a higher observed prevalence rate of suicidal ideation and participation in suicidal behavior than their male peers, while suicide attempts resulting in death is higher for male adolescents due to the utilization of more lethal means (e.g., firearms) by males (Nock et al., 2013; CDC, 2014; Kann et al., 2016).

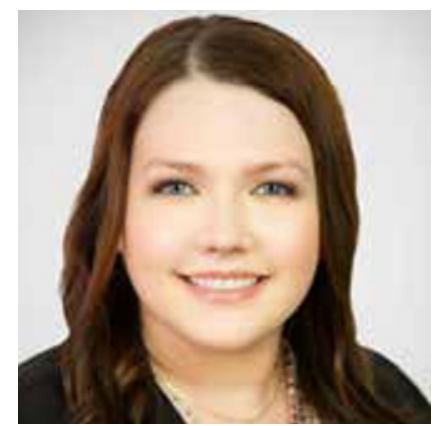

Kristin L. Wolfe, MRC, is a doctoral candidate at the University of Texas Southwestern Medical Center. She has served as the research coordinator for a recent NIMH R34 examining a brief intervention for suicide risk reduction in high adolescents. Her current research focus is on utilizing technology for safety planning in adolescents with suicidality.

Similar analyses were conducted for ethnicity. Individuals who were identified as American Indian, Eskimo, and Aleut were at greatest risk for death by suicide $(18.2 / 100,000)$, followed by White $(10.6 / 100,000)$, Asian, Pacific Islander, $(7.0 / 100,000)$ and Black $(6.1 / 100,000)$ youth (CDC, 2005).

A national survey conducted in 2015 (Kann et al., 2016) polled American high school students to garner a better sense of health risk behaviors, including suicidality. Of the more than 15,000 students surveyed, almost $18 \%$ had contemplated suicide within the past year. The survey found that $14.6 \%$ had made a plan to engage in suicidal behavior, $8.6 \%$ had made at least one suicide attempt, and $2.8 \%$ had made an attempt that was severe enough to warrant medical attention.

Adolescents who have experienced suicidality are likely to continue to struggle with these thoughts and behaviors throughout their adult lives (Goldman-Mellor et al., 2014), in addition to other psychiatric comorbidities. This reinforces the fact that adolescence is an important time period for interventions and long-term psychological change. 


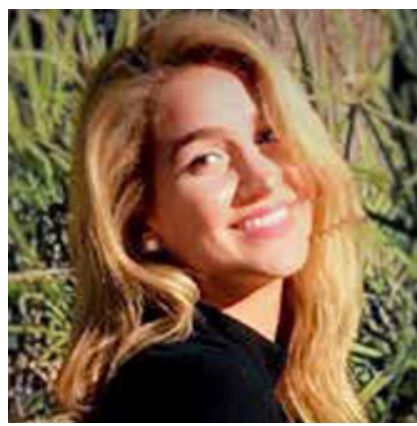

Katia M. Goga is a research coordinator for the Pediatric Psychiatry Research Program at UT Southwestern Medical Center. She is the study coordinator for a study examining the effects of an inpatient targeted intervention and safety plan phone application on suicide prevention. Ms. Goga received her Bachelor of Science degree from the University of Texas at Austin in psychology.

\section{Risk Factors}

Pinpointing risk factors for suicidality in youth is imperative for assessing risk. While there are no universally predictive patterns, research has revealed some differences in adolescents who engage in suicidal behaviors and those who do not (Franklin et al., 2017). Most risk factor research is done at the group level, which limits its value with individual cases. You need to assess each individual adolescent in their unique setting and circumstance to develop a treatment plan specific to that patient's personal needs.

The onset of puberty is associated with an increase in rates of suicide attempts (Gould, Greenberg, Velting, \& Shaffer, 2003). The prevalence of suicide plans and attempts increases steadily after the age of 12, with the rate of increase slowing at the age of 15 (Nock et al., 2013). Ethnicity is also relevant, with American Indian and Alaska Native youth having the highest percentage of suicide attempts (Borowsky, 1999). Furthermore, identifying as a sexual minority has been shown to be a risk factor for suicidal behaviors (Kann et al., 2011).

Mood disorders (e.g., depression and bipolar disorder) are most commonly associated with suicidal threat, but other psychological disorders (e.g., conduct disorders, substance use disorder, post-traumatic stress disorder, psychosis, eating disorders, anxiety disorders) have also been shown to be related to suicidality (Bridge, Goldstein, \& Brent, 2006). Other clinical characteristics, such as sleep disturbances (Emslie et al., 2012), nonsuicidal self-injury (Klonsky, May, \& Glenn, 2012), and prior suicide attempts (Miranda et al., 2014), have also been shown to be important factors to assess.

Interpersonal difficulties have been shown to be related to the presence of suicidality in youth (Johnson et al., 2002); specifically, conflicts with one's family or peers (Kodish et al., 2016). Physical and sexual abuse have also been found to be risk factors (Cash \& Bridge, 2009). Cognitive variables, such as rumination, hopelessness, and thinking errors (Burke et al., 2016; DeCamp \& Bakken, 2016), may also play a role in suicidality.
It is important to assess situational and environmental factors that may require safety interventions. Access to lethal means (e.g., firearms) has been shown to be associated with death by suicide, even when controlling for psychiatric illnesses (Brent et al., 1993). Bullying has also been identified as a contributing factor to suicidal risk in adolescents (Kim \& Leventhal, 2008). Making the environment safe includes working with the client and their caregivers to ensure that the proper safety plans and school policies are put into place.

\section{Beginning the Clinical Contact}

\section{Obtaining Informed Consent}

Proper consent and assent documents must be obtained, along with discussion of limits of confidentiality. Typically, for outpatient treatment, consent is obtained from the legal guardian of the adolescent through a signed informed consent document. Caregivers should be given opportunities to ask questions, and you should take care to explain their role in treatment as well as the limits of confidentiality.

Upon obtaining parental consent, a similar process is utilized with the adolescent to obtain assent. This includes explaining the therapeutic process, the role of the adolescent, caregiver, and therapist, as well as the limits of confidentiality. The caregiver, adolescent, and therapist all need to agree about what will be disclosed to the parent and what will remain between the therapist and adolescent. It is important to use this time to make sure everyone understands that safety and suicidality concerns are always going to be addressed among all three parties.

\section{Possible Use of Screening Forms}

Prior to the clinical interview, self-report instruments can be helpful in assessing risk. This is easily done while administrative and other matters are being addressed. It can be done using paper and pencil forms or on a computer or iPad.

It is not uncommon for adolescents to disclose suicidal thoughts and behaviors on a self-report instrument but not in the interview (Duggal et al., 2000). The SIQ (Suicidal Ideation Questionnaire; Reynolds, 1987), and the CHRT (Concise Health Risk Tracking Scale; Trivedi et al., 2011; Mayes et al., 2018) are both self-report measures with good psychometric properties. A clinician-administered structured interview, such as the Ask Suicide-Screening Questions (ASQ; Horowitz et al., 2012) or the Columbia-Suicide Severity Rating Scale (C-SSRS) screening version (Posner et al., 2008) can be used when it is desired to integrate the screening into the clinical process and provide more structure.

If necessary, depression measures (e.g., Patient Health Questionnaire [PHQ-9; Kroenke et al., 2001]; Quick Inventory 


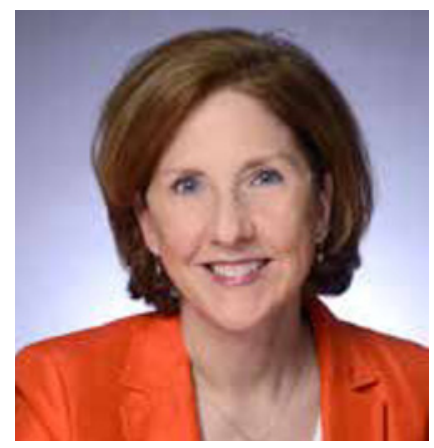

Betsy D. Kennard, PsyD, has extensive experience in pediatric depression and has served as a site co-investigator in three NIMH funded multisite treatment studies of adolescent depression and suicide. Her recent work has focused on developing interventions to improve outcomes of youth with suicidal thoughts and behaviors. She is also the Program Director of an intensive outpatient program for suicidal youth at Children's Health, Dallas.

of Depressive Symptomatology [QIDS; Rush et al., 2006], Children's Depression Rating Scale-Revised [CDRS-R; Poznanski, Freeman, \& Mokros, 1985]), specific symptom measures (e.g., hopelessness [Beck Hopelessness Scale, BHS; Beck et al., 1974], interpersonal concerns [Interpersonal Needs Questionnaire, INQ; Van Orden et al., 2008], or sleep [Pittsburgh Sleep Quality Index, PSQI; Buysse et al., 1989]) may be employed if relevant.

\section{Engaging the Client}

Engaging the client is one of the most difficult, but most important, components of assessment and treatment. SommersFlanagan (2018) suggests the clinician should utilize a range of skills and techniques to aid in initiating conversations about current life events, interpersonal relationships, and suicidal thoughts and impulses. These include building rapport, showing empathy, staying balanced, and not being afraid to directly ask about suicidal ideation (or attempts). Utilizing open-ended questions regarding precipitating factors, current life stressors, or any additional concerns will help inform the broad psychological and interpersonal context of the events. When a suicidal attempt has occurred, it is useful to use a normative frame and obtain concrete information about stress using mood scaling with a suicide floor (see Sommers-Flanagan, 2018, for a description of their use).

Conducting a standard initial intake interview to address the chief complaint or presenting problem is recommended for patients presenting without predetermined risk for suicide. Some adolescents, however, have suicidal thoughts but have not expressed them to anyone. It is important to ask about suicidal thoughts and impulses even in nonobvious clinical situations with troubled adolescents. The goal is to be able to tentatively place the case in one of three risk categories: a negative screen, potential risk, or imminent risk (Horowitz et al., 2012). A negative screen indicates that no immediate suicide intervention is necessary. Those who endorse suicidality or came in specifi- cally for suicide concerns fall into the potential or imminent risk category. For both imminent and potential risk, a more in-depth analysis of the overall situation and the most recent events are needed. Table 1 provides a guide to the preliminary assessment of adolescents that includes suicidal risk assessment.

\section{Assessment of Suicidal Risk}

Use a "chain analysis" of events, thoughts, and vulnerabilities leading up to a suicide event to help understand the contributing factors (Miller, Rathus, \& Linehan, 2007; Brent, Poling, \& Goldstein, 2011). The use of such a functional analysis of the suicidal event is a way to reconstruct events, thoughts, and feelings leading up to the suicide attempt with a "freeze frame" view (Wexler, 1991).

Begin by having the adolescent describe the problematic situation and events. Ask them to be as detailed as possible in describing what they did, thought, and felt at the time. Ask about their understanding of the thoughts, feelings, and behaviors of others with whom they were interacting. The adolescent should then go on to describe the precipitating event(s) that led up to the suicide attempt. This includes describing the environment, any known causes for the event, as well as the thoughts, feelings, and behaviors of the adolescent. This can provide a rich description, which allows the opportunity to identify earlier points in behavioral patterns for possible intervention that would change the direction of the events and lead to a different outcome.

The next step is to collaboratively examine the vulnerability factors. This is done by asking the adolescent about their thoughts on what factors contributed to the event. They may describe being tired, having intense emotions, or misusing an illicit substance prior to the event. The key to the chain analysis is to help the adolescent be as detailed as possible so that you can collaboratively find places where skills could have been used and determine any alternative solutions or prevention strategies.

Obtaining collateral information regarding an adolescent with suicidality is imperative. Important information can be gathered from caregivers, family members, school personnel, or other significant individuals in their life. Gathering this external information helps fill in the gaps that adolescents are unsure of or unwilling to tell you.

The chain analysis and other interviewing will help you assess the adolescent's insight into their overall life situation, their handling of strong feelings and conflict, and their suicidality. Having this more detailed information will help in the development of your treatment plan and/or disposition plan. The best suicide prevention approach is to eliminate the factors triggering the suicidal thoughts and behavior. 
Table 1. Steps for Preliminary Assessment

\section{Identify Events That Brought Patient to Treatment}

Risk for Suicide Not Obtain proper consent.

Obvious

Discuss limits of confidentiality.

Use self-report measures such as:

- Self Report Instruments

- SIQ (Suicidal Ideation Questionnaire)

- CHRT (Concise Health Risk Tracking Scale)

- Clinician-Administered Interview

- Columbia Suicide Severity Rating Scale

Conduct standard intake interview.

Ask about suicidal thoughts and impulses.

Adolescent Presents

With Suicidal

Ideation, Intent, or

Recent Attempts

\section{Obtain proper consent.}

Discuss limits of confidentiality.

Use self-report measures such as:

- Self-Report Instruments

- SIQ (Suicidal Ideation Questionnaire)

- CHRT (Concise Health Risk Tracking Scale)

- Clinician-administered interview

- Columbia-Suicide Severity Rating Scale

Conduct standard intake interview.

Ask about suicidal thoughts and impulses.

Gather information about history with suicidality to confirm no active suicidal thoughts. If suicidal thoughts are active, confirm there is no plan or intent to act upon them.

Maintain safety: Have parent or caretaker available that can monitor and supervise adolescent as needed; limit access to means, safety plan must be factored into disposition.

Conduct chain analysis:

- Specify the problem behavior: Adolescent should be as detailed as possible in describing what they did, thought, and felt at the time.

- Describe precipitating event(s) that led to suicide attempt: Adolescent should describe environment, known causes of the event, thoughts, feelings, and behaviors.

- Examine the vulnerability factors: Ask adolescent what factors contributed to the event (may describe being tired, having intense emotions, misusing illicit substance prior to event).

\section{Determine Screen}

Negative Screen

No intervention necessary (though clinical judgment can override this decision)

Potential Risk

Adolescent endorsed suicidality but denied having current ideation. Adolescent should be evaluated for safety and disposition planning.

Imminent Risk
Adolescent endorsed current ideation. Adolescent should be evaluated for safety and disposition planning. 
For those in the potential or imminent risk category, the next step is to determine if the client and their family can leave the office and maintain safety. It is up to you to assess their history with suicidality and their current level of suicidality (e.g., suicidal thoughts, plans). The environment must be considered as well. To remain safe at home, the adolescent needs to be in an environment where (a) there are supportive caregivers who can monitor and support the youth and (b) access to lethal means such as firearms, medications, and sharp objects has been or will be restricted. If the client is not a current danger to themself and has an appropriate environment to return to, they are likely safe to return home and continue therapy on an outpatient basis.

\section{Ongoing Assessment for Suicide}

In working with suicidal patients, it is important to include routine assessment of mood along with assessment of urges to selfharm, suicidal thoughts, and behaviors. This is consistent with a measurement-based care approach. It enables the clinician to assess improvement and, most importantly, detect worsening that may require a change in treatment plan.

\section{Guidelines for Treatment}

The first step to treatment is determining the necessary level of care based on the assessment. Passive suicidal ideation may be managed on an outpatient basis, while active ideation with plan and intent may require a higher level of care (such as an intensive outpatient program or inpatient hospitalization). Level of care should be determined by the severity of the suicidality, the overall needs of the adolescent and family, and an assessment of the safety risks in the environment.

The treatment plan should be developed collaboratively with the adolescent and their caregivers. It is critical to ensure that the treatment plan is acceptable and feasible from the perspective of both the adolescent and family. Strategies for maintaining safety will be one component.

Ensuring quality care may require consultation with other providers on their care team. For example, for patients moving from outpatient to inpatient, you would want to reach out to their outpatient providers to discuss goals for inpatient care. Similarly, upon discharging from the hospital it is important to collaborate with their outpatient team (or to help them find an outpatient provider) to facilitate appropriate linkage to care.

\section{Evidence-Based Treatments for Suicidal Adolescents}

Within each setting, there are a variety of evidence-based treatments that you could implement with your client. As explained in more detail below, forms of cognitive behavioral therapy, dialectical behavioral therapy, and mentalization-based therapy are recommended for use due to their large effect size shown by a recent meta-analysis (Ougrin et al., 2015). Below are some of the most efficacious treatments (see Table 2 for links to the supporting research and additional readings).

Safety planning (e.g., Samra \& Bilsker, 2007; Stanley \& Brown, 2012). A safety plan is a strategy to aid the client in maintaining safety until their next treatment session. Clients are taught a specific set of coping strategies and a method to establish sources of support. Components of the safety plan include making the environment safe, identifying warning signs that may lead to thoughts of self-harm, and developing a list of contacts the client can turn to in time of need. You will teach the client how to identify a potential precipitant (e.g., fighting with a parent about school work), methods of internal coping (e.g., listening to music), methods of external coping (e.g., seeing a movie with a friend), and you will provide clinical contacts (e.g., your contact information or that of an on-call therapist).

The client's caregivers are also involved in safety planning, in which they are encouraged to identify barriers that may prevent implementation of the safety plan, modify precipitants if possible through a temporary truce or school visit, identify coping mechanisms, and learn about the emotional thermometer. You should also discuss access to lethal means with your client and their caregivers, including medications, poisons, or other agents that can be used for suicidal action. If there is access to guns at home, as in the presented scenario, talk directly with the gun owner to remove the weapon (Brent et al., 1993). If the caregivers refuse to remove their weapons from the home, you should work with the family to come up with some form of safe storage. Safety planning has been shown to be efficacious in research settings and real-world settings, but it is typically only a portion of the treatment plan and is most commonly used in conjunction with therapeutic and/or psychopharmacological interventions.

Family-focused treatment. With theoretical foundations in attachment theory, family-focused therapy concentrates on promoting the innate desire for a secure relationship in the family environment to create a sense of security and support (Diamond, Russon, \& Levy, 2016). At the center of the treatment, you work to unveil and resolve experiences or relational processes that might be negatively affecting the relationship between the adolescent and their caregiver. Sessions with adolescents and their caregivers are conducted both individually and jointly. In your sessions with the adolescent, you will guide the adolescent in understanding the dysfunction in their relationship with their caregivers, while working to improve caregiving motivation and emotional attunement throughout your sessions with the caregiver.

Dialectical behavior therapy. Dialectical behavior therapy (DBT) is a comprehensive, evidence-based cognitive behavioral treatment in which you focus on engaging the client in treat- 
Table 2. Evidence-Based Treatment Resources

\begin{tabular}{|c|c|c|}
\hline $\begin{array}{l}\text { Evidence-Based } \\
\text { Treatment }\end{array}$ & Article & Additional Web Resources \\
\hline Safety Planning & $\begin{array}{l}\text { "Safety Planning Intervention: A Brief Inter- } \\
\text { vention to Mitigate Suicide Risk" at https:// } \\
\text { www.sciencedirect.com/science/article/pii/ } \\
\text { S1077722911000630 }\end{array}$ & $\begin{array}{l}\text { https://suicidepreventionlifeline.org/wp-content/up- } \\
\text { loads/2016/08/Brown_StanleySafetyPlanTemplate. } \\
\text { pdf } \\
\text { http://www.comh.ca/publications/resources/pub_cwst/ } \\
\text { cwst.pdf }\end{array}$ \\
\hline $\begin{array}{l}\text { Family-Focused } \\
\text { Treatment }\end{array}$ & $\begin{array}{l}\text { "Attachment-Based Family Therapy: A Review } \\
\text { of the Empirical Support" at https://onlineli- } \\
\text { brary.wiley.com/doi/abs/10.1111/famp.12241 }\end{array}$ & $\begin{array}{l}\text { https://afsp.org/can-family-focused-cognitive-behav- } \\
\text { ior-therapy-reduce-suicidal-ideation-in-young-chil- } \\
\text { dren-with-bipolar-disorder/ } \\
\text { https://afsp.org/teen-just-made-suicide-attempt-now/ }\end{array}$ \\
\hline $\begin{array}{l}\text { Dialectical Behavior } \\
\text { Therapy }\end{array}$ & $\begin{array}{l}\text { "Efficacy of Dialectical Behavior Therapy } \\
\text { for Adolescents at High Risk for Suicide" at } \\
\text { https://jamanetwork.com/journals/jamapsychia- } \\
\text { try/article-abstract/2685324 }\end{array}$ & $\begin{array}{l}\text { https://www.mdedge.com/psychiatry/article/64223/ } \\
\text { depression/adapting-dialectical-behavior-therapy- } \\
\text { help-suicidal-adolescents } \\
\text { https://afsp.org/dialectal-behavioral-therapy-dbt-actu- } \\
\text { ally-change-way-brain-works/ } \\
\text { https://www.healio.com/psychiatry/suicide/ } \\
\text { news/online/\%7B832a9aae-5306-4beb-87b3- } \\
\text { 6214bc800378\%7D/dialectical-behavior-therapy- } \\
\text { benefits-suicidal-teens }\end{array}$ \\
\hline $\begin{array}{l}\text { Cognitive Behavioral } \\
\text { Therapy for Suicide } \\
\text { Prevention (CBT-SP) }\end{array}$ & \begin{tabular}{|l|} 
"Cognitive Behavior Therapy for Suicide Pre- \\
vention (CBT-SP): Treatment Model, Feasibil- \\
ity and Acceptability" at https://www.ncbi.nlm. \\
nih.gov/pmc/articles/PMC2888910/ \\
\end{tabular} & $\begin{array}{l}\text { https://www.med.uio.no/klinmed/forskning/sentre/ } \\
\text { nssf/aktuelt/arrangementer/nasjonale-konferanser/7- } \\
\text { nasjonale-konferanse-2011/plenar_Stanley_CBT.pdf }\end{array}$ \\
\hline The SAFETY Program & $\begin{array}{l}\text { "The SAFETY Program: A Treatment-Devel- } \\
\text { opment Trial of a Cognitive-Behavioral Family } \\
\text { Treatment for Adolescent Suicide Attempters" } \\
\text { at https://www.ncbi.nlm.nih.gov/pmc/articles/ } \\
\text { PMC4289426/ }\end{array}$ & $\begin{array}{l}\text { https://afsp.org/safety-program-family-intervention- } \\
\text { emergency-departments/ }\end{array}$ \\
\hline $\begin{array}{l}\text { Mentalization-Based } \\
\text { Treatment }\end{array}$ & $\begin{array}{l}\text { "Mentalization-Based Treatment for Self-Harm } \\
\text { in Adolescents: A Randomized Controlled } \\
\text { Trial" at https://www.sciencedirect.com/sci- } \\
\text { ence/article/pii/S0890856712007368 }\end{array}$ & $\begin{array}{l}\text { https://www.rcpsych.ac.uk/pdf/RCPMentaliz- } \\
\text { ing30.11.16.pdf }\end{array}$ \\
\hline
\end{tabular}

ment and reducing self-harm and suicide attempts. Through DBT, you nonjudgmentally guide the client in acknowledging the consequences of their destructive behaviors and teach skills that are aimed to improve emotional regulation, distress tolerance, and ultimately build a life worth living. DBT has been shown to be an effective intervention in reducing self-harm and suicidal ideation in adolescents (McCauley et al., 2018; Mehlum et al., 2014).
Cognitive behavioral therapy for suicide prevention (CBTSP) (Stanley et al., 2009). CBT-SP was created specifically as a manualized intervention to implement cognitive behavioral therapy with adolescents who had made a recent suicide attempt.

CBT-SP addresses suicidality through aiding the adolescent in developing skills to help them cope more effectively and refrain from engaging in suicidal behavior. Risk factors related to 
suicidality (e.g., stress, family concerns, negative cognitions) are identified through conducting a chain analysis and are specifically targeted through an acute treatment phase. Based on retention rates from the preliminary study, this treatment appears acceptable with $72.4 \%$ of the adolescents attending at least 12 individual sessions.

Acute treatment is comprised of a variety of modules, which can be chosen based on the presenting concerns of the adolescent. Safety planning, chain analysis, assessing suicide risk and hopelessness, and relapse prevention constitute the foundation of the intervention, but optional modules (e.g., cognitive restructuring, mood monitoring, emotion regulation) can be used at the therapist's discretion. Upon completion of the acute phase, CBT-SP implements a continuation phase which is typically comprised of 12 weeks and up to six additional individual sessions and three family sessions. The purpose of this time frame is to ensure that the adolescent has the appropriate skills to discontinue treatment. Specifically, the manual guides the therapist to help the adolescent prepare for potential situations that may arise.

The SAFETY program. The SAFETY program, created by Asarnow and colleagues (2015), is a twelve-week cognitive behavioral intervention designed to reduce suicide risk and increase teen safety. Targeting both the youth and their caregiver, the SAFETY program focuses on the SAFETY pyramid-fostering safe settings, safe people, safe activities and actions, safe thoughts, and safe stress reactions to reduce the presence of suicidality. To address these skills, the SAFETY program includes a parent therapist, an adolescent therapist, and a family component, which allows the adolescent and parent to work together on cementing the skills they have learned.

To foster safe behaviors, the program begins with psychoeducation, identification of family strengths, introduction of an emotional thermometer, and safety planning in conjunction with a detailed chain analysis. The second phase of the intervention is skills-based training for the youth and utilizing skills such as creating hope boxes, reasons for living, problem-solving, distress tolerance, and emotion regulation. During this time, parents receive psychoeducation focusing around topics such as communication, problem solving, understanding depression, and family care. The final phase of the intervention focuses on relapse prevention and linkage to additional outpatient care if warranted.

Mentalization-based treatment for adolescents (MBT-A; Rossouw et al., 2012). Mentalization-based therapy (MBT) was created to address self-harming behaviors in youth. Mentalization, defined by the authors as "the capacity to understand actions in terms of thoughts and feelings," is thought to be an important component in reducing intentional self-harm. This manualizedbased treatment focuses on increasing both the adolescent's and the family's ability to understand these self-harming behaviors within a mentalization framework. MBT-A was created to be conducted over a one-year time period and is comprised of weekly individual sessions and monthly family sessions. Sessions are primarily meant to focus on the regulation of affect and impulsivity. Ideally, these sessions will aid the adolescent and their family in understanding and accurately portraying emotions, even in situations with heavy emotional valence. By addressing the adolescent's actions in terms of mentalization, self-harm and depression levels both decrease upon completion of treatment.

\section{Ethical Considerations}

Ensuring ethical treatment of adolescents presenting with suicidality rests on ensuring that you are prepared to provide such care. Almost all ethical considerations can be addressed through proper training and by ensuring competency to treat this population. The Suicide Prevention Resource Center (SPRC, 2006) has listed seven primary domains, with a total of 24 competencies across them, required to be competent to treat suicidality. This list has recently been streamlined (Cramer et al., 2013) into a list of 10 core competencies. While the specifics of each list vary, the overarching message appears to be the same: Clinicians should be cognizant of their emotional reactions to suicide and be able to empathically treat this population, have a working knowledge of risk factors and treatment modalities in order to determine the level of risk and create an appropriate treatment plan, follow proper legal and institutional policies regarding documentation and reporting procedures, and implement proper self-care strategies to prevent burnout or compassion fatigue. By following these basic guidelines, you help to ensure adherence to the ethical principles set forth by the American Psychological Association's ethics code (APA, 2017).

\section{Conclusion}

Despite efforts aimed at improving outcomes in those who suffer from suicidal thoughts and behaviors, adolescent suicide rates have been increasing over the past decade. Increased screening, particularly in hospital settings has been an important change in health care (Horowitz et al., 2012). Training in suicide assessment - including screening and brief intervention-is critical for clinicians working with adolescents. Clinicians working with populations at high risk for suicidal behavior should be well versed in evidence-based interventions that reduce suicidal risk. In particular, adolescents who are discharged from inpatient care may require extra attention and clinical care. The period after hospital discharge is a time of vulnerability for suicide attempt (Olfson, Marcus, \& Bridge, 2014; Bridge, Goldstein, \& Brent, 2006). Screening tools, suicide assessment, chain analysis, safety planning, and evidence-based treatment strategies are important to incorporate into a treatment plan when working with adolescents with suicidal thoughts and behaviors. Training in suicide assessment, treatment planning, and brief interventions - including those that promote treatment engagement (Miller \& Rollnick, 2013) - is an area that has great potential for improving outcomes in suicidal youth.

References available at NationalRegister.org 


\section{Assessing and Treating Adolescent Suicidality}

\section{References}

American Psychological Association (2017). Ethical Principles of Psychologists and Code of Conduct. [online] Retrieved from: http://www.apa.org/ethics/code/

Asarnow, J. R., Berk, M., Hughes, J. L., \& Anderson, N. L. (2015). The SAFETY Program: a treatmentdevelopment trial of a cognitive-behavioral family treatment for adolescent suicide attempters. Journal of Clinical Child \& Adolescent Psychology, 44(1), 194-203.

Beck, A.T., Weissman, A., Lester, D., \& Trexler, L. (1974). The measurement of pessimism: the hopelessness scale. Journal of consulting and clinical psychology, 42(6), 861.

Borowsky, I. W., Resnick, M. D., Ireland, M, \& Blum, R. W. (1999). Suicide attempts among American Indian and Alaska Native youth. Archives of Pediatric and Adolescent Medicine, 153(6), 573-580. doi: 10.1001/archpedi.153.6.573

Brent, D. A., McMakin, D. L., Kennard, B. D., Goldstein, T. R., Mayes, T. L., \& Douaihy, A. B. (2013). Protecting adolescents from self-harm: a critical review of intervention studies. Journal of the American Academy of Child \& Adolescent Psychiatry, 52(12), 1260-1271.

Brent, D. A., Perper, J. A., Moritz, G., Allman, C, Friend, A, Roth, C, ... Baugher, M (1993). Psychiatric risk factors for adolescent suicide: a case-control study. Journal of the American Academy of Child and Adolescent Psychiatry, 32(3), 521-529. doi: 10.1097/00004583-199305000-00006

Brent, D. A., Poling, K. D., \& Goldstein, T. R. (2011). Treating depressed and suicidal adolescents: A clinician's guide. New York, NY, US: Guilford Press.

Bridge, J. A., Goldstein, T. R., Brent, D. A. (2006). Adolescent suicide and suicidal behavior. J Child Psychol Psychiatry, 47(3/4):372-394

Burke, T. A., Connolly, S. L., Hamilton, J. L., Stange, J. P., Abramson, L. Y., \& Alloy, L. B. (2016). Cognitive risk and protective factors for suicidal ideation: A two year longitudinal study in adolescence. Journal of Abnormal Child Psychology, 44, 1145-1160.

Buysse, D. J., Reynolds III, C. F., Monk, T. H., Berman, S. R., \& Kupfer, D. J. (1989). The Pittsburgh Sleep Quality Index: a new instrument for psychiatric practice and research. Psychiatry research, 28(2), 193-213.

Cash, S. J. \& Bridge, J. A. (2009). Epidemiology of youth suicide and suicidal behavior. Current Opinion in Pediatrics. 21(5):613-619. doi: 10.1097/MOP.0b013e32833063e1.

Centers for Disease Control and Prevention (2015). Leading causes of death reports, national and regional, 1999-2015. Retrieved from webappa.cdc.gov/sasweb/ncipc/leadcaus10 us.html 
Centers for Disease Control and Prevention, National Center for Injury Prevention and Control. (2015). Web-based Injury Statistics Query and Reporting System (WISQARS) Fatal Injury Data Visualization. Retrieved from URL: https://wisqars-viz.cdc.gov/

Cramer, R.J., Johnson, S.M., McLaughlin, J., Rausch, E.M., Conroy, M. A. (2013). Suicide Risk Assessment Training for Psychology Doctoral Programs: Core Competencies and a Framework for Training. Training and education in professional psychology, 7(1):1-11. doi:10.1037/a0031836.

DeCamp, W., \& Bakken, N. W. (2016). Self-injury, suicide ideation, and sexual orientation: Differences in causes and correlates among high school students. Journal of Injury and Violence Research, 8(1), 15-24.

Diamond, G., Russon, J., Levy, S. (2016). Attachment-based family therapy: A review of the empirical support. Fam Process, 55(3):595-610. DOI:10.1111/famp.12241.

Duggal, S., Malkoff-Schwartz, S., Birmaher, B., Anderson, B. P., Matty, M. K., Houck, P. R., ... \& Frank, E. (2000). Assessment of life stress in adolescents: Self-report versus interview methods. Journal of the American Academy of Child \& Adolescent Psychiatry, 39(4), 445-452.

Emslie, G. J., Kennard, B. D., Mayes, T. L., Nakonezny, P. A., Zhu,L., Tao, R., ... Croarkin, P. (2012). Insomnia moderates outcome of serotonin-selective reuptake inhibitor treatment in depressed youth. Journal of Child and Adolescent Psychopharmacology,22(1), 21-28. doi:

10.1089/cap.2011.009

Figley, C. R. (2002), Compassion fatigue: Psychotherapists' chronic lack of self-care. J. Clin. Psychol., 58: 1433-1441. doi:10.1002/jclp.10090

Franklin, J. C., Ribeiro, J. D., Fox, K. R., Bentley, K. H., Kleiman, E. M., Huang, X., ... \& Nock, M. K. (2017). Risk factors for suicidal thoughts and behaviors: A meta-analysis of 50 years of research. Psychological Bulletin, 143(2), 187.

Goldman-Mellor, S.J., Caspi, A., Harrington, H., Hogan, S., Nada-Raja, S., Poulton, R., Moffitt, T.E. (2014). Suicide Attempt in Young People- A Signal for Long-term Health Care and Social Needs. JAMA Psychiatry, 71(2):119-127. doi:10.1001/jamapsychiatry.2013.2803

Horowitz, L. M., Bridge, J. A., Teach, S. J., Ballard, E., Klima, J., Rosenstein, D. L., ... \& Pao, M. (2012). Ask Suicide-Screening Questions (ASQ): a brief instrument for the pediatric emergency. department. Archives of pediatrics \& adolescent medicine, 166(12), 1170-1176.

Johnson, J. G., Cohen, P., Gould, M. S., Kasen, S., Brown, J., \& Brook, J. S. (2002). Childhood adversities, interpersonal difficulties, and risk for suicide attempts during late adolescence and early adulthood. Archives of General Psychiatry, 59(8), 741-749.

Kann, L., McManus, T., Harris, W.A., et al. (2016). Youth Risk Behavior Surveillance - United States, 2015. MMWR Surveill Summ; 65(No. SS-6):1-174. DOI: http://dx.doi.org/10.15585/mmwr.ss6506a1

Kann, L., Olsen, E. O., McManus, T., Kinchen, S., Chyen, D., Harris, W. A., et al. (2011). Sexual identity, sex of sexual contacts, and health risk behaviors among students in grades 9-12-youth risk behavior surveillance, selected sites, United States, 2001-2009. MMWR Surveillance Summaries, 60, 1-133. 
Kim, Y. S., \& Leventhal, B. (2008). Bullying and suicide. A review. International journal of adolescent medicine and health, 20(2), 133-154.

Klonsky, E. D., May, A. M., \& Glenn, C. R. (2013). The relationship between nonsuicidal self-injury and attempted suicide: converging evidence from four samples. Journal of Abnormal Psychology, 122(1), 231-237. doi: 10.1037/a0030278

Kodish, T., Herres, J., Shearer, A., Atte, T., Fein, J., \& Diamond, G. (2016). Bullying, depression, and suicide risk in a pediatric primary care sample. Crisis, 37(3), 241-6.

Kroenke, K., Spitzer, R. L., \& Williams, J. B. W. (2001). The PHQ-9: Validity of a Brief Depression Severity Measure. Journal of General Internal Medicine, 16(9), 606-613. http://doi.org/10.1046/j.1525-1497.2001.016009606.x

Mayes. T., Kennard, B.D., Foxwell, A.A., Hughes, J., Smith, M., Lau, J., Komachi, C., \& Emslie, G.J. (2015, October). Feasibility and Acceptability of a Suicide Prevention Intensive Outpatient Program. Poster presented at the 62nd American Academy of Child and Adolescent Psychiatry, San Antonio, TX.

Mayes, T. L., Kennard, B. D., Killian, M., Carmody, T., Grannemann, B., Rush, A. J., ... \& Trivedi, M. H. (2018). Psychometric properties of the concise health risk tracking (CHRT) in adolescents with suicidality. Journal of affective disorders.

McCauley, E., Berk, M.S., Asarnow, J.R., et al. (2018). Efficacy of Dialectical Behavior Therapy for Adolescents at High Risk for Suicide A Randomized Clinical Trial. JAMA Psychiatry. Published online June 20, 2018. doi:10.1001/jamapsychiatry.2018.1109

Mehlum, L., Tørmoen, A. J., Ramberg, M., Haga, E., Diep, L. M., Laberg, S., ... \& Grøholt, B. (2014). Dialectical behavior therapy for adolescents with repeated suicidal and self-harming behavior: a randomized trial. Journal of the American Academy of Child \& Adolescent Psychiatry, 53(10), 10821091.

Miller, A.L., Rathus, J.H., \& Linehan, M.M. (2007). Dialectical behavior therapy with suicidal adolescents. New York, NY, US: Guilford Press.

Miller, W.R., Rollnick, S. (2013). Motivational Interviewing: Helping People Change, (3rd ed.). New York, NY, US: Guilford Press.

Miranda, R., De Jaegere, E., Restifo, K., \& Shaffer, D. (2014). Longitudinal follow-up study of adolescents who report a suicide attempt: aspects of suicidal behavior that increase risk of a future attempt. Depression and Anxiety, 31(1), 19-26.doi: 10.1002/da.22194

Olfson, M., Marcus, S.C., Bridge, J.A. (2014). Focusing Suicide Prevention on Periods of High Risk. JAMA. 2014;311(11):1107-1108. doi:10.1001/jama.2014.501

Ougrin, D., Tranah, T., Stahl, D., Moran, P., \& Asarnow, J. R. (2015). Therapeutic interventions for suicide attempts and self-harm in adolescents: systematic review and meta-analysis. Journal of the American Academy of Child \& Adolescent Psychiatry, 54(2), 97-107.

Plemmons, G., Hall, M., Doupnik, S., Gay, J., Brown, C., Browning, W., ... \& Rehm, K. (2018). Hospitalization for Suicide Ideation or Attempt: 2008-2015. Pediatrics, e20172426. 
Posner, K., Brent, D., Lucas, C., Gould, M., Stanley, B., Brown, G., \& Mann, J. (2008). Columbia-Suicide Severity Rating Scale (C-SSRS). Columbia University Medical Center.

Poznanski, E.O., Freeman, L.N., \& Mokros, H.B. (1985). Children's Depression Rating Scale Revised. Psychopharmacol Bull, 21: 979-989.

Reynolds, W. M. (1987). Suicidal ideation questionnaire (SIQ). Odessa, FL: Psychological Assessment Resources.

Rossouw, T. I., \& Fonagy, P. (2012). Mentalization-based treatment for self-harm in adolescents: a randomized controlled trial. Journal of the American Academy of Child \& Adolescent Psychiatry, 51(12), 1304-1313.

Rush, A. J., Bernstein, I. H., Trivedi, M. H., Carmody, T. J., Wisniewski, S., Mundt, J. C., ... \& Fava, M. (2006). An evaluation of the quick inventory of depressive symptomatology and the hamilton rating scale for depression: a sequenced treatment alternatives to relieve depression trial report. Biological psychiatry, 59(6), 493-501.

Samra, J. \& Bilsker, D. (2007). Coping with Suicidal Thoughts. Consortium for Organizational Mental Health (COMH). Obtained from http://www.comh.ca/publications/resources/pub_cwst/cwst.pdf.

Sommers-Flanagan, J. (2018). Conversations About Suicide: Strategies for Detecting and Assessing Suicide Risk. Journal of Health Services Psychology, 44, 33-45.

Sommers-Flanagan, J., \& Shaw, S. L. (2017). Suicide risk assessment: What psychologists should know. Professional Psychology: Research and Practice, 48(2), 98.

Stanley, B. \& Brown G.K. (2012). Safety planning intervention: A brief intervention to mitigate suicide risk. Cognitive and Behavioral Practice, 19, 256-264. http://doi.org: 10.1016/j.cbpra.2011.01.001

Stanley, B., Brown, G., Brent, D. A., Wells, K., Poling, K., Curry, J., ... \& Goldstein, T. (2009). Cognitivebehavioral therapy for suicide prevention (CBT-SP): treatment model, feasibility, and acceptability. Journal of the American Academy of Child \& Adolescent Psychiatry, 48(10), 1005-1013.

Suicide Prevention Resource Center (2006). Core competencies in the assessment and management of suicidality. Newton, MA: Author.

Trivedi, M. H., Wisniewski, S. R., Morris, D. W., Fava, M., Gollan, J. K., Warden, D., ... \& Zisook, S. (2011). Concise Health Risk Tracking scale: a brief self-report and clinician rating of suicidal risk. Journal of Clinical Psychiatry, 72(6), 757.

Van Orden, K. A., Witte, T. K., Gordon, K. H., Bender, T. W., \& Joiner Jr, T. E. (2008). Suicidal desire and the capability for suicide: Tests of the interpersonal-psychological theory of suicidal behavior among adults. Journal of consulting and clinical psychology, 76(1), 72.

Wexler, D. (1991). The PRISM workbook: A program for innovative self-management. New York: W.W. Norton \& Company. 